\title{
Sudemycin K: A Synthetic Antitumor Splicing Inhibitor Variant with Improved Actiyity and Versatile Chemistry
}

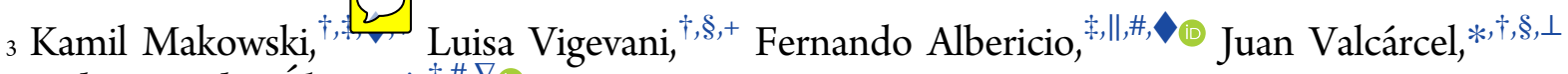
4 and Mercedes Álvarez ${ }^{*}+\#, \#, \nabla_{(0)}$

$5{ }^{\dagger}$ Centre for Genomic Regulation (CRG), The Barcelona Institute of Science and Technology, Dr. Aiguader 88, 08003 Barcelona, 6 Spain

$7{ }^{\ddagger}$ Institute for Research in Biomedicine (IRB-Barcelona), Baldiri i Reixac 10, 08028, Barcelona, Spain

$8{ }_{8}^{\S}$ Universitat Pompeu Fabra (UPF), Dr. Aiguader 88, 08003 Barcelona, Spain

9 "Department of Organic Chemistry, Faculty of Chemistry, University of Barcelona, Martí Franqués 1, 08028 Barcelona,Spain

$10{ }^{\perp}$ ICREA, Pg. Lluís Companys 23, 08010 Barcelona, Spain

11 \#CIBER-BBN, Networking Centre on Bioengineering, Biomaterials and Nanomedicine, Barcelona, Spain

$12 \nabla^{\nabla}$ Laboratory of Organic Chemistry, Faculty of Pharmacy, University of Barcelona, Joan XXIII s/n, 08028 Barcelona, Spain

14 ABSTRACT: Important links exist between the process of 15 pre-mRNA splicing and cancer, as illustrated by the frequent 16 mutation of splicing factors in tumors and the emergence of 17 various families of antitumor drugs that target components of 18 the splicing machinery, notably SF3B1, a protein subunit of 19 spliceosomal U2 small nuclear ribonucleoprotein particle 20 (snRNP). Sudemycins are synthetic compounds that harbor 21 a pharmacophore common to various classes of splicing 22 inhibitors. Here, we describe the synthesis and functional 23 characterization of novel sudemycin analogues that function24 ally probe key groups within this pharmacophore. 25 Our results confirm the importance of a conjugated diene 26 group and in addition reveal significant spatial flexibility in this 27 region of the molecule. Sudemycin K, a derivative that replaces

28 the pharmacophore's oxycarbonyl by an amide group, displays improved potency as an inhibitor of cancer cell proliferation, as a 29 regulator of alternative splicing in cultured cells and as an inhibitor of in vitro spliceosome assembly. Sudemycin K displays higher 30 stability, likely related to the replacement of the oxycarbonyl group, which can be a substrate of esterases, by an amide group. The 31 activity and special reactivity of sudemycin $\mathrm{K}$ can pave the way to the synthesis and evaluation of a variety of novel sudemycin 32 derivatives.

33 he high incidence of cancer and severe limitations in 34 current therapies (e.g., side effects and drug resistance) 35 make the identification of new drugs and targets an area of 36 intense investigation in oncology. Several small molecules 37 targeting components of the RNA splicing machinery have 38 been shown to display antitumor properties. ${ }^{1-3}$ Of relevance, 39 recent findings indicate that the splicing machinery can indeed 40 be limiting for the proliferation of cancer cells, and 41 consequently splicing inhibition can confer therapeutic 42 vulnerability to Myc oncogene-driven cancers. ${ }^{4,5}$

43 RNA splicing is the process by which introns are removed 44 from mRNA precursors (pre-mRNAs) and is achieved by the 45 spliceosome, composed of five small nuclear RiboNucleoPro46 tein complexes (U1, U2, U4, U5, and U6 snRNPs) and more 47 than 200 additional polypeptides. ${ }^{6,7}$ Introns are recognized via 48 specific sequence signals located at their boundaries: a short 49 (6-8 nucleotides) consensus at the $5^{\prime}$ splice site $\left(5^{\prime}\right.$ ss $)$ and

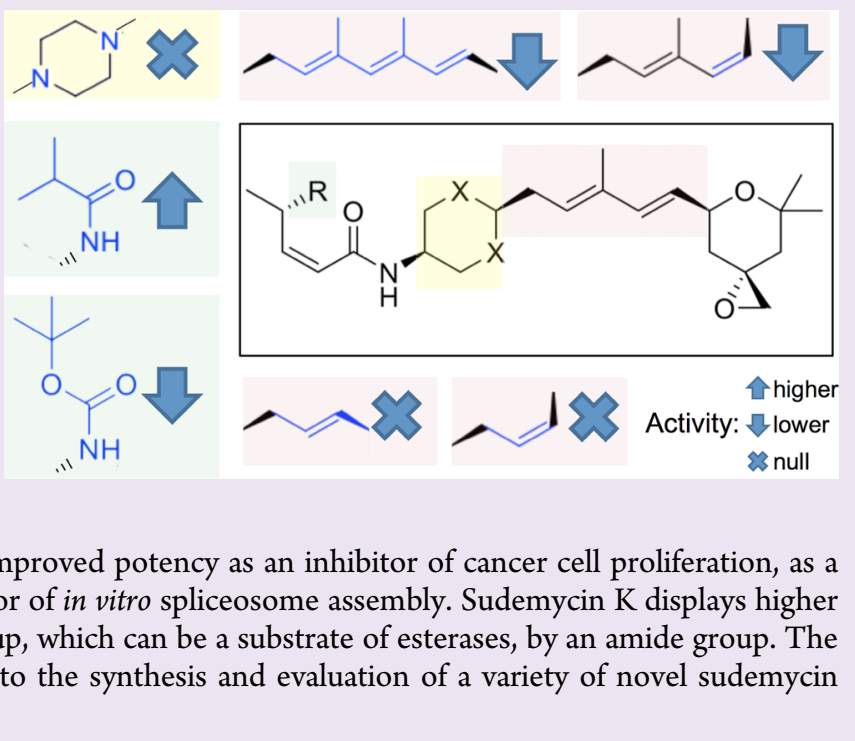

three sequence elements at the $3^{\prime}$ splice site $\left(3^{\prime} \mathrm{ss}\right)$. The latter 50 include the branch point sequence (containing an adenosine 51 involved in $2^{\prime}-5^{\prime}$ phosphodiester bond formation with the $5^{\prime} 52$ end of the intron after the first catalytic step of the splicing 53 reaction), a polypyrimidine tract, and a conserved AG 54 dinucleotide at the $3^{\prime}$ end of the intron. The first steps of 55 spliceosome assembly include the recognition of the 5'ss by U1 56 snRNP and of the branch point sequence by U2 snRNP, both 57 involving base-pairing interactions between the corresponding 58 small RNA components (snRNAs) and the pre-mRNA., 59

SF3B1 is a protein component of SF3B, a subcomplex within 60 U2 snRNP implicated in branch point recognition. Mutations 61

Received: June 29, 2016

Accepted: November 8, 2016

Published: November 8, 2016 


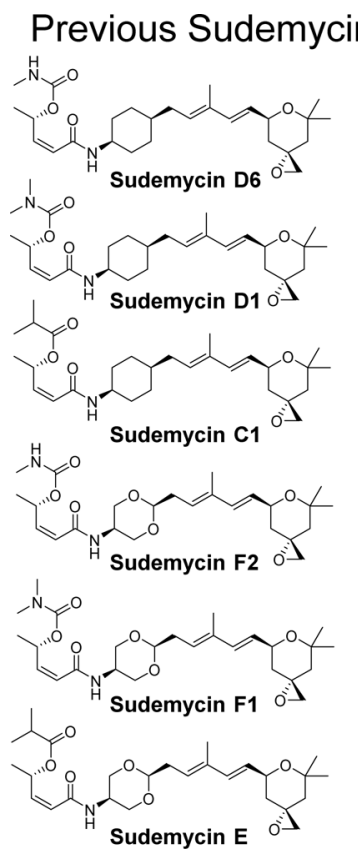

\section{Sudemycins Variants}

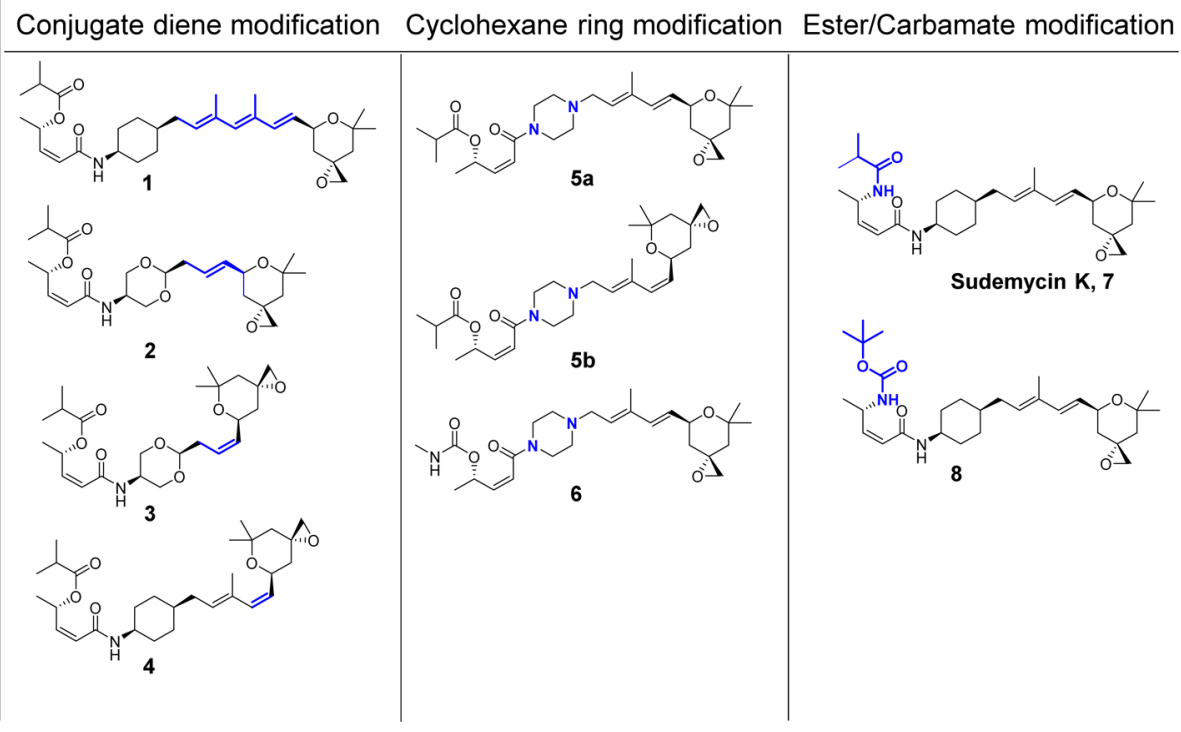

Figure 1. Chemical structure of sudemycins and variants tested in this study. The general feature of each class of modification is indicated and modifications highlighted in blue. Sudemycin F2 was previously described as compound $19 \mathrm{n} .{ }^{47}$

62 in SF3B1, as well as in other $3^{\prime}$ splice site-recognizing factors, 63 are recurrent in cancer. ${ }^{1,8}$ SF3B1 mutations are particularly 64 frequent in myelodysplastic syndromes with refractory anemia 65 and ring sideroblasts (RARS) 9,10 and in chronic lymphocytic 66 leukemia (CLL). ${ }^{11-13}$ In CLL, SF3B1 mutants correlate with 67 resistance to chemotherapy and poor prognosis. ${ }^{11-13}$ Notably, 68 SF3B1 was identified as the physical target of drugs that display 69 higher cytotoxicity in tumor cells than in normal cells and are 70 therefore promising therapeutic candidates. ${ }^{1,14-18}$

71 Several natural compounds isolated from bacterial fermenta72 tion products display these properties, including FR901464, 73 pladienolides, FD-895, GEX1A, herboxidiene, and thailansta74 tines. $^{19-23}$ Stabilized derivatives SSA (spliceostatin A, 75 FR901464-related) and E7107 (pladienolide-related) were 76 shown to inhibit splicing and bind tightly to the SF3B 77 complex. $^{17,18}$ Similar results were obtained for herboxidiene. ${ }^{15}$ 78 Thus, the SF3B complex has emerged as a target of 79 representative drugs in each of the three main classes of 80 natural compounds (spliceostatin, pladienolides, and herbox81 idienes). The spliceostatin analogue meayamycin was shown to 82 display antitumor effects at picomolar concentrations. ${ }^{14}$

83 The drug spliceostatin A binds SF3B1 and prevents its 84 interaction with the pre-mRNA, concomitant with interactions 85 of U2 snRNA with "decoy" sequences upstream of their 86 productive binding site at the branch point sequence. ${ }^{24}$ In 87 addition, the drug E7107 alters the balance between alternative 88 U2 snRNA conformations, also destabilizing U2 snRNP 89 recruitment. $^{25}$ Interestingly, cancer-associated SF3B1 mutations 90 induce cryptic $3^{\prime}$ splice site selection through the use of 91 upstream branch points. ${ }^{26,27}$ Thus, SF3B1 appears to be 92 involved in multiple interactions important for U2 snRNP 93 binding that are relevant for the control of cell proliferation and 94 apoptosis.

95 How can drugs targeting a core component of the splicing 96 machinery not result in general cellular toxicity? Tumor cells 97 often display an altered balance of alternative isoforms that 98 prevent apoptosis, promote proliferation, and invasion. ${ }^{28}$
Transcriptome-wide analyses have identified drug-induced 99 changes in alternative splicing that particularly affect genes 100 involved in cell division, apoptosis, and cancer progression, ${ }^{24} 101$ suggesting that these compounds differentially affect alternative 102 splice sites. Moreover, recent results indicate that these drugs 103 can have beneficial therapeutic effects for chronic lymphocytic 104 leukemia (CLL) and for melanoma cells displaying drug 105 resistance. $^{29,30}$ Notably, leukemic cells with spliceosomal 106 mutations display also increased sensitivity to splicing 107 inhibitors. $^{31,32}$

A well-characterized alternative splicing event relevant for 109 antitumor drug function involves inclusion/skipping of exon 2110 in the three-exon gene coding for myeloid cell leukemia 1111 (MCL1) proteins. This protein belongs to the Bcl-2 family of 112 apoptosis regulators, displays antiapoptotic functions, and is 113 overexpressed in several tumors. ${ }^{33-35}$ Due to its rapid turnover 114 both at protein and at RNA levels, MCL1 is highly affected by 115 transcription and translation inhibitors, causing the death of 116 some tumor cells depending on the levels and activity of Bcl-X, 117 another alternatively spliced apoptotic regulator. ${ }^{35}$ Exon 2118 skipping leads to the production of a pro-apoptotic protein ${ }^{36} 119$ and could therefore facilitate therapeutic effects. Interestingly, 120 recent studies show that MCL1 is highly sensitive to splicing 121 inhibition, as depleting several splicing factors induces MCL1 122 exon 2 skipping. ${ }^{37-39}$ Indeed, MCL1 alternative splicing was 123 found to be the most affected by SF3B1-targeting splicing 124 inhibitors among a panel of alternative splicing events involved 125 in proliferation and apoptosis control. ${ }^{39}$ Indeed, spliceostatin A 126 induces apoptosis in chronic lymphocytic leukemia (CLL) cells 127 through MCL1 downregulation, ${ }^{29}$ and resistant cell lines 128 reacquire sensitivity to $\mathrm{Bcl}$-X-targeting drugs when treated 129 with meayamycin, due to MCL1 regulation. ${ }^{40}$ 130

Despite their very different overall skeletons, SF3B-targeting 131 molecules share a common pharmacophore, ${ }^{41}$ which includes a 132 conjugated diene, an epoxide, and an oxycarbonyl group 133 (Figure 1). While the epoxide group was found not to be $134 \mathrm{fl}$ absolutely required for activity, it contributes to increasing 135 
136 it. ${ }^{19,42-44}$ On the basis of this pharmacophore, a total synthetic 137 compound series known as sudemycins has been described. ${ }^{45}$ 138 In spite of their simplified structure, containing up to six 139 sterocenters less than natural products, these drugs retain 140 potent anticancer activity in vitro and in vivo, ${ }^{45}$ as well as the 141 ability to target SF3B1. ${ }^{15}$ Previous extensive structure-activity 142 relationship (SAR) studies reported by Webb's group led to the 143 synthesis of stable active derivatives, described as sudemycin C1 144 (cyclohexane core) and sudemycin E (dioxane core; ${ }^{41,45,46}$ 145 Figure 1). Challenging synthetic hurdles included the develop146 ment of a synthetic route for the heterocyclic spiro moiety with 147 two stereocenters, present in all the sudemycins, and the diene 148 linker with $E, E$ configuration. The sterocenter in position 2 of 149 the pyrane ring was induced by organocatalic reduction of 150 double bond using a McMillan catalyst, and the spiroepoxide 151 was prepared by diastereoselective introduction of dimethyl152 sulfoxonium methylide to the ketone. The key step for 153 preparation of diene was the Julia-Kocienski olefination. In a 154 recent study, ${ }^{47}$ the synthetic route was revised, and the Julia155 Kocienski step was optimized by shifting the sulfone and 156 aldehyde group positions required for the olefination, which in 157 comparison to the previously described procedures resulted in 158 better diastereoselectivity and yield. Additionally, new 159 sudemycin derivatives, mostly with ester moiety modification, 160 were reported, among them sudemycin D6, which is the most 161 potent sudemycin so far, displaying improved solubility, ${ }^{47}$ 162 bearing a methylcarbamate group instead of the isobutyric 163 group present in sudemycins $\mathrm{C} 1$ and $\mathrm{E}$ (Figure 1).

164 With the aim of further exploring the chemical space of this 165 family of drugs, we have designed and synthesized several novel 166 sudemycin analogues aimed to probe key chemical features and 167 exploring possibilities for further derivatization of the structural 168 frame.

\section{RESULTS AND DISCUSSION}

170 We aimed to test (a) the function of the conjugated diene, 171 which is part of the common pharmacophore of three classes of 172 splicing inhibitors, (b) the function of the oxycarbonyl moiety, 173 another key element of the pharmacophore, and (c) the 174 identity of the cyclohexane ring that links the previous two 175 moieties. In addition, the most active previously described 176 sudemycins D6, D1, C1, F1, F2, ${ }^{47}$ and E (Figure 1), were 177 prepared in parallel, using procedures reported by the Webb's 178 group $^{47}$ and used for biological activity comparison with the 179 new derivatives. The epoxide group was not modified in our 180 study because previous work already showed that it contributes 181 but is not absolutely required for activity. ${ }^{19,42-44}$

182 The activity of the compounds was tested in in vitro 183 biochemical assays of spliceosome (complex A) assembly and 184 in cell culture assays by assessing MCL1 alternative splicing 185 regulation and cytotoxicity. The structure of the drug variants 186 and their activities are summarized in Figure 1 and Table 1, 187 respectively.

188 Conjugated Diene Modifications. Previous studies 189 indicated that the conjugated diene is important for the activity 190 of Sudemycins and other drugs. ${ }^{41}$ To test the relevance of this 191 moiety's length, $\mathbf{1}$, the triene harboring three $\mathrm{E} \cap$ ugate 192 double bonds, and 2 , a derivative harboring only one wouble 193 bond, were obtained. To evaluate the importance of the 194 stereochemistry of double bonds for biological activ (y, 195 additional compounds 3 and 4, harboring a double bond in 196 configuration, were also prepared.
Table 1. Summary of Sudemycin Variants' Activities ${ }^{a}$

\begin{tabular}{|c|c|c|c|}
\hline drus & $\begin{array}{l}\text { in vitro } \mathrm{A}^{\prime} \text { complex } \\
\text { formation, } \mathrm{IC}_{50} \\
(\mathrm{nM})\end{array}$ & $\begin{array}{c}\text { MCL1 alternative } \\
\text { splicing regulation, } \mathrm{IC}_{50} \\
(\mathrm{nM})\end{array}$ & $\begin{array}{l}\text { cytotoxicity in } \\
\text { HeLa cells, IC } \text { IC }_{50} \\
\text { (nM) }\end{array}$ \\
\hline $\begin{array}{l}\text { Sud K } \\
\quad(7)\end{array}$ & $\approx 250$ & $\approx 15$ & $2.3 \pm 0.81$ \\
\hline $\begin{array}{l}\text { Sud } \\
\text { D6 }\end{array}$ & $\approx 500$ & $\approx 250$ & $6.3 \pm 0.82$ \\
\hline $\begin{array}{l}\text { Sud } \\
\text { D1 }\end{array}$ & $\approx 750$ & $\approx 630$ & $109 \pm 48$ \\
\hline 4 & $\approx 40000$ & $\approx 6300$ & $12703 \pm 16386$ \\
\hline 1 & $\approx 30000$ & $\approx 12500$ & $>30000$ \\
\hline $\begin{array}{l}\text { Sud } \\
\text { C1 }\end{array}$ & $\approx 400$ & $\approx 320$ & $123 \pm 154$ \\
\hline Sud E & $\approx 10000$ & $\approx 2000$ & $764 \pm 113$ \\
\hline $\begin{array}{l}\text { Sud } \\
\text { F1 }\end{array}$ & $\approx 12000$ & $\approx 3500$ & $646 \pm 38$ \\
\hline $\begin{array}{l}\text { Sud } \\
\text { F2 }\end{array}$ & $\approx 50000$ & $\approx 1200$ & $417 \pm 0.00$ \\
\hline 8 & n.d. & $\approx 40000$ & $848 \pm 200$ \\
\hline 2 & n.d. & $>100000$ & $>30000$ \\
\hline 3 & n.d. & $>100000$ & n.d. \\
\hline $5 a$ & n.d. & $>100000$ & $>30000$ \\
\hline $5 b$ & n.d. & $>100000$ & $>30000$ \\
\hline 6 & n.d. & $>100000$ & $>30000$ \\
\hline
\end{tabular}

${ }^{a}$ Summary of activities of the compounds tested in this study. Biochemical assays to evaluate complex A3' formation, RT-PCR assays to evaluate effects on MCL1 alternative splicing regulation, and cytotoxicity assays were carried out and quantified as described in the Methods section (Supporting Information). Estimates of $\mathrm{IC}_{50}$ values are provided. Sud: abbreviation for Sudemycin. n.d.: not detected at the maximum concentration tested $(100 \mu \mathrm{M}$ for cytotoxicity assays, 1 $\mathrm{mM}$ for in vitro spliceosome assembly assay).

The synthesis of triene 1 was performed (Scheme 1) using $197 \mathrm{~s} 1$ the known aldehyde $\mathbf{9}^{47}$ as starting material. Transformation of 198 aldehyde 9 into 10 required three synthetic steps: Wittig 199 elongation with $\mathrm{Ph}_{3} \mathrm{P}=\mathrm{CH}-\mathrm{CO}_{2} \mathrm{Et}$ prepared in situ from 200 corresponding phosphonium salt, reduction of the ester to 201 allylic alcohol, and oxidation of alcohol to generate aldehyde 202 10. Modified Julia-Kocienski olefination between the aldehyde 203 10 and sulfone $11^{4} \bigcirc$ forded triene 12 with excellent 204 diastereoselectivity (E atio 96:4). The transformation of 205 compound 12 into 1 required the following steps: chemo- 206 selective reduction of azide functional group of $\mathbf{1 2}$ to amine 207 followed by coupling with (S,Z)-4-(tert-butyldimethylsilyloxy)- 208 pent-2-enoic acid, ${ }^{48}$ alcohol deprotection, and formation of 209 ester with isobutyric anhydride. During the amide formation, 210 isomerization of the $Z$ double bond in the $\alpha$ position was 211 produced $(Z / E$ ratio $7: 3)$. The $Z / E$ mixture was purified by RP- 212 HPLC, and pure 1 was obtained.

The preparation of $\mathbf{2}$ with only one double bond between the 214 dioxane ring and spiro moiety started from aldehyde $13^{46}$ and 215 follows a similar sequence of reactions as described for 1. 216 However, the generation of olefin $\mathbf{1 4}$ by Julia-Kocienski was not 217 diastereoselective. A diasteromeric mixture of $E$ and $Z$ olefins 218 was converted to alcohol $\mathbf{1 5}$ in three steps, and then both 219 diastereoisomers were separated using the RP-HPLC semi- 220 preparative technique. Stereochemistry of $E$ and $Z$ double was 221 assigned by ${ }^{13} \mathrm{C}$ NMR. Sterically compressed carbon nuclei 222 produce shielding effects; ${ }^{49}$ thus, in $Z$ olefin, it shows a 33.7 and 223 64.6 ppm chemical shift of carbons affected and $E$ olefin 38.3224 and $69.1 \mathrm{ppm}$, respectively. Finally, esterification of both 225 alcohols led to corresponding isobutyric esters 2 and 3 . 226 
Scheme 1. Syntheses of $1,2,3$, and $4^{a}$<smiles>CC(C=O)=CC[C@H]1CC[C@H](N)CC1</smiles>

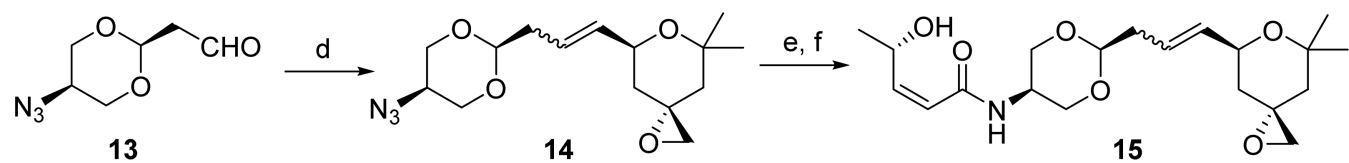

ref. 5
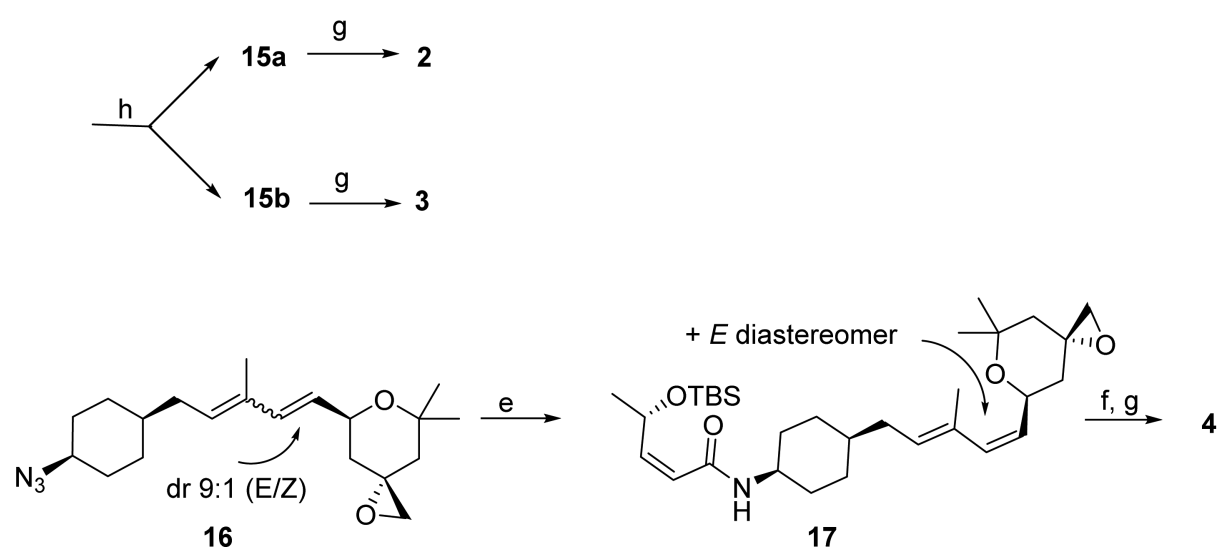

a (a) (1-Ethoxy-1-oxopropan-2-yl)triphenylphosphonium bromide, $t$ - $\mathrm{BuOK}, \mathrm{CH}_{2} \mathrm{Cl}_{2}, 0{ }^{\circ} \mathrm{C}$ to $\mathrm{rt}, 50 \%$; (b) $\mathrm{DIBALH}^{\circ} \mathrm{CH}_{2} \mathrm{Cl}_{2},-78{ }^{\circ} \mathrm{C}, 93 \%$; $(\mathrm{c})$ Dess-Martin periodinane, $\mathrm{CH}_{2} \mathrm{Cl}_{2}, 0{ }^{\circ} \mathrm{C}$, 70\%; (d) 11, NaHMDS, THF, $-78{ }^{\circ} \mathrm{C}$ to $\mathrm{rt}, 80 \%$ for $12,42 \%$ for 14 ; (e) (1) $\mathrm{Ph}_{3} \mathrm{P}$, benzene, $55{ }^{\circ} \mathrm{C}$; (2) $(S, Z)$-4-(tert-butyldimethylsilyloxy)pent-2-enoic acid, $\mathrm{HBTU}, \mathrm{NEt}_{3}, \mathrm{ACN}, 0{ }^{\circ} \mathrm{C}$ to $\mathrm{rt} 81 \%$ for $15,75 \%$ for 17 ; (f) $\mathrm{TBAF}, \mathrm{THF}, 0{ }^{\circ} \mathrm{C}$ to $\mathrm{rt}, 77 \%$ for 15 , $80 \%$ for 4 ; $(\mathrm{g})$ isobutyric anhydride, $\mathrm{NEt}_{3}, 4-\mathrm{DMAP}, \mathrm{CH}_{2} \mathrm{Cl}_{2}, 0{ }^{\circ} \mathrm{C} 79 \%$ for $2,76 \%$ for $3,80 \%$ for 4 ; (h) RP-HPLC semipreparative separation. Bt = 2-benzo[d]thiazole

227 proved protocol of preparation of diene 16 developed by 228 Webb produces diasteromeric mixture $E, E$ an $(E$, with a ratio 229 of 9:1. In our hands, this mixture as well as $B S$ protected 230 alcohol could be separated by column chromatography, and a 231 pure sample of $\mathbf{1 7}$ was collected and converted into sudemycin $232 \mathrm{C} 1$ diastereoisomer, compound 4 (Scheme 1).

233 When these derivatives were tested for activity, reduction to a 234 single double bond (in both $E$ and $Z$ diasteroisomer 235 configurations, 2 and 3, Figure 1) completely suppressed the 236 drug's activity, while the 1 triene displayed highly reduced but 237 still detectable activity in splicing assays but negligible in
239 the other hand, the Z,E,Z diastereomer of sudemycin $\mathrm{C} 1$, 240 harboring opposite stereochemistry at the double bond (4,

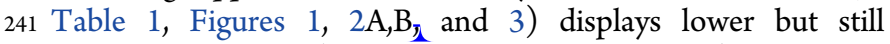
242 significant activities (particularly in cytotoxic assays) despite the 243 dramatic change in spatial orientation of key pharmacophore 244 components (Table 1).

245 Cyclohexane Substitution by Piperazine or 1,3246 Dioxane. In previous studies, substitution of the cyclohexane 247 ring by a dioxane improved drug solubility. ${ }^{46}$ With the aim of 248 further increasing aqueous solubility, three novel compounds 249 harboring piperazine rings were synthesized (5a, 5b, and 6, 250 Figure 1).
The formation of the sudemycin derivatives with a piperazine 251 core (Scheme 2) started from commercially available tert-butyl $252 \mathrm{~s} 2$ 4-(2-hydroxyethyl)piperazine-1-carboxylate (18). Chain elon- 253 gation of 18 and transformation into alcohol 19 as unique $E 254$ diastereoisomers required the following: Swern oxidation of 18; 255 Wittig olefination with $\mathrm{Ph}_{3} \mathrm{P}=\mathrm{CH}-\mathrm{CO}_{2} \mathrm{Et}$; and reduction of 256 ester using DIBALH. Confirmation of $E$ stereochemistry was 257 possible based on a lack of signals when performing 1D-NOE 258 irradiation at $\delta=6.8 \mathrm{ppm}$ and $\delta=1.8 \mathrm{ppm}$ (see the Supporting 259 Information). At this point, the BOC protecting group was 260 removed with TFA, and free secondary amine was coupled with 261 (S,Z)-4-(tert-butyldimethylsilyloxy)pent-2-enoic acid. Then, 262 alcohol was oxidized with Dess-Martin periodinane, generating 263 20. This aldehyde and sulfone $\mathbf{5}$ were used for Julia-Kocienski 264 olefination, rendering 21 ( $d r$ 8:2). Removal of the TBS 265 protecting group and esterification with the isobutyric 266 anhydride of $\mathbf{2 2}$ produce a mixture of final compounds 5a 267 and $\mathbf{5 b}$ that were arated by semipreparative RP-HPLC. In 268 order to prepare 20 mate 6, the diastereomeric mixture of 21269 was first purified; then the TBS group was removed and the 270 alcohol was activated as a carbonate with nitropheny hor- 271 oformate and finally treated with methylamine to obtain the 272 desired carbamate. 
A

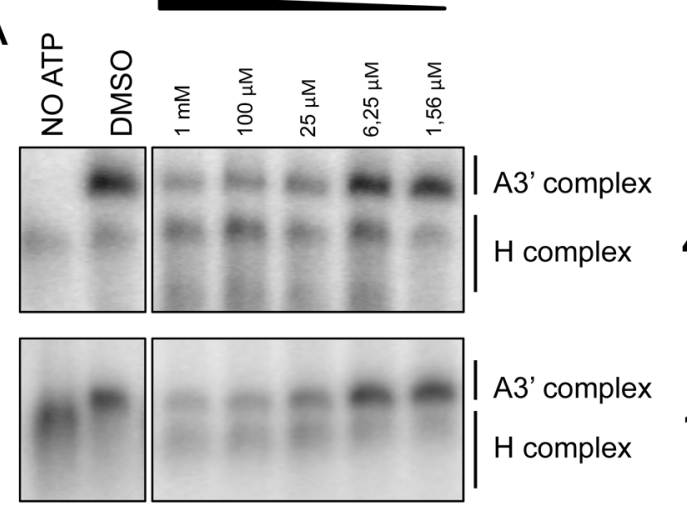

C

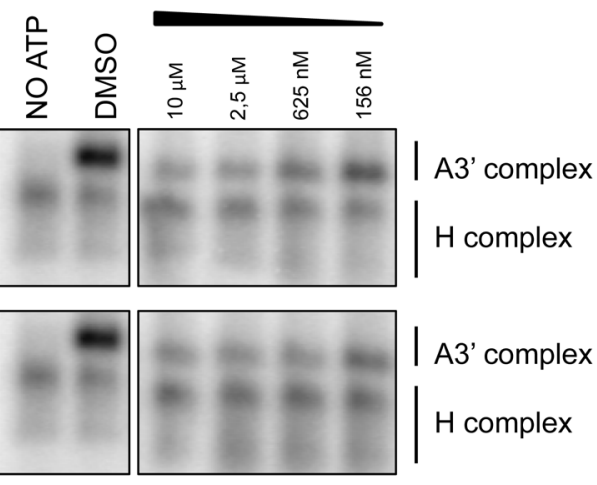

$E$

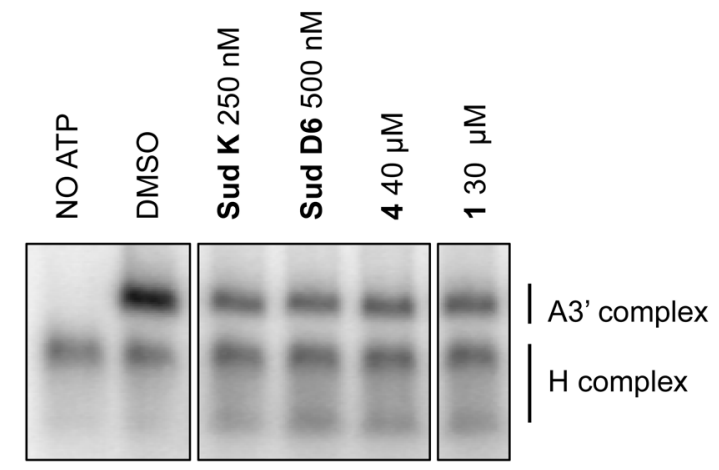

G

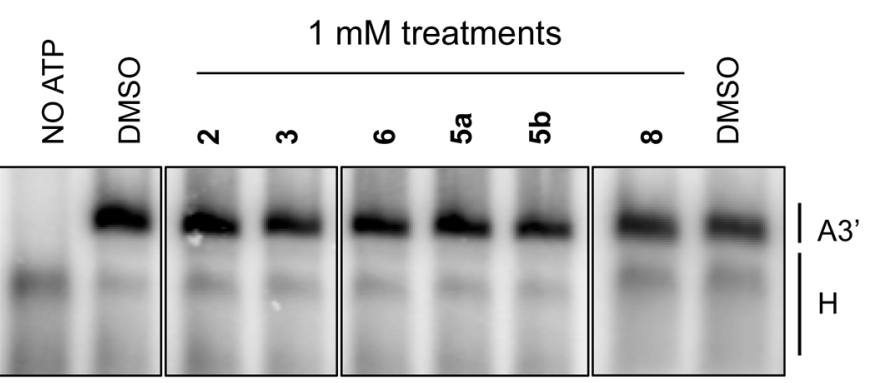

B

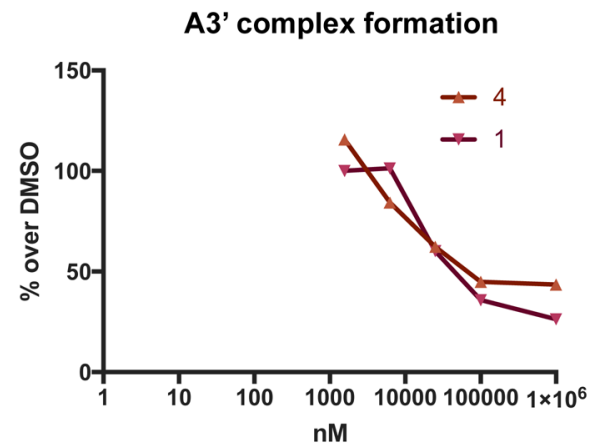

$\mathrm{D}$

A3' complex formation

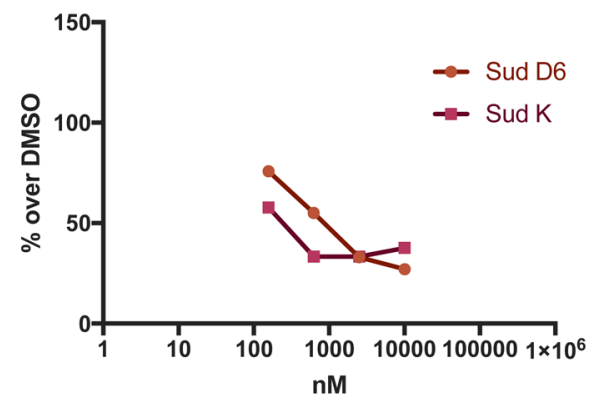

$\mathrm{F}$

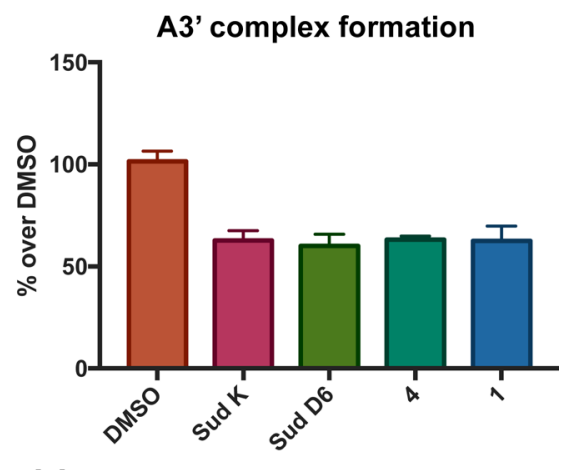

$\mathrm{H}$

A3' complex formation

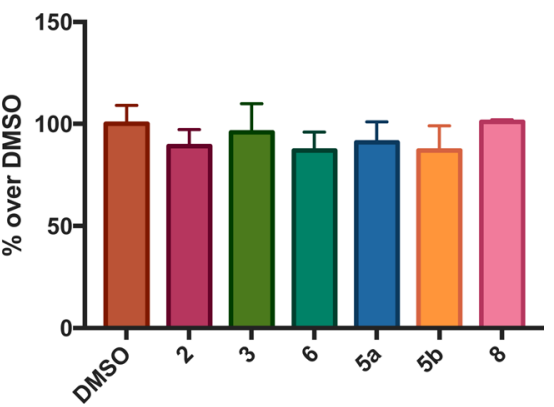

Figure 2. In vitro spliceosome (A3' complex) formation assays. (A) Representative Phosphoroimager pictures of electrophoretic separation of $\mathrm{H}$ and A3' complexes assembled upon incubation of a radioactively labeled adenovirus major late promoter RNA (spanning sequences corresponding to $3^{\prime}$ half of intron 1 and part of the following exon) in HeLa nuclear extracts and fractionation on nondenaturing arape gels. The electrophoretic mobility of $\mathrm{A3}^{\prime}$ and $\mathrm{H}$ complexes is indicated, as well as concentrations of the indicated drugs ( 1 and $\mathbf{4}$, conjug iene variants) or DMSO as control. Only complex $\mathrm{H}$ is formed in the absence of ATP. (B) Quantification of the percentage of A3' complex formation for a range of concentrations of the indicated drugs, corresponding to the results reported in A. (C) Results equivalent to those in A, for sudemycins D6 and K. (D) Quantification of the results reported in C, as in B. (E) Analyses as in A for the indicated drugs and concentrations. The goal of the experiment 
Figure 2. continued

was mpare in parallel the different concentrations of various drugs causing a 50\% decrease in A3' complex formation. (F) Quantifications of resul 2 in E, corresponding to triplicate experiments. Differences between drugs were not significant $(t$ test), while they were all significantly different from the control DMSO treatment ( $p$ value $<0.01$ ndard deviations are indicated. $(\mathrm{G})$ Analyses as in $\mathrm{E}$ at $1 \mathrm{mM}$ drug concentrations (maximal concentrations tested). (H) Quantification of resu in G, corresponding to triplicate experiments. Drug effects were not significantly different from control DMSO treatment $(t$ test). Standard deviations are indicated.

274 These compounds showed very low activity in splicing or cell 275 proliferation tests and no detectable activity in in vitro assays, 276 revealing the requirement of the cyclohexane ring for 277 sudemycin's function (Table 1, Figures 2G,H and 3). In 278 agreement with previous results, ${ }^{47}$ substitution of sudemycin 279 D6 cyclohexyl group by a dioxane also reduced strongly the 280 drug's activity (sudemycin F2, ${ }^{47}$ Figure $\rightarrow$ Table 1, Figure 3, 281 Supporting Information Figure 1A and

282 Oxycarbonyl group modifications: Sudemycin K. The 283 oxycarbonyl group is another key element of the common 284 pharmacophore. As reported by Webb and colleagues, ${ }^{46}$ a free 285 alcohol at this position dramatically decreases the activity 286 compared to ester derivatives. To further explong other 287 chemical moieties at this position, we prepared $\&$ pounds 288 with amide or carbamate groups instead of ester (sudemycin $\mathrm{K}$ 289 or 7 and 8, Figure 1). As amide groups are less susceptible to 290 hydrolysis than ester groups, these compounds might display 291 higher stability and efficacy.

292 Sudemycin K was obtained by reaction of the acid 27 with 293 the amine previously obtained in the reduction of azide $\mathbf{1 6}$ 294 (Scheme 3). The acid 27 was obtained from commercially 295 available $L$-alanine methyl ester hydrochloride by trans296 formation into amide $\mathbf{2 4}$ followed by ester reduction to 297 aldehyde $\mathbf{2 5}$. Olefination of $\mathbf{2 5}$ to give Z-26 was achieved using 298 Still-Gennari protocol with good diastereoselectivity $(d r=$ 299 92:8). The hydrolysis of ester Z-26 using conventional methods $300(\mathrm{LiOH}, \mathrm{NaOH})$ led to decomposition; however, using milder 301 reagents like trimethyltin hydroxide, the desired acid with 302 moderate yield was obtained. Acid 30 needed for the 303 preparation of carbamate $\mathbf{8}$ was obtained in a similar way 304 (Scheme 3) starting from commercial aldehyde 28. The main 305 advantage of this synthetic process lies in greater convergence 306 and fewer synthetic steps than previously described, with a 307 similar yield.

308 Replacing the oxycarbonyl by an amide group (sudemycin $\mathrm{K}$, 309 Figure 1) resulted in a compound with higher activity than 310 sudemycin D6, the most potent sudemycin described so far, 311 both in biochemical spliceosome assembly assays as well as in 312 cellular assays for MCL1 alternative splicing and for cytotoxicity 313 (Table 1, Figures 2C-F and 3). The solubility of sudemycin $\mathrm{K}$ 314 and D6 was found to be comparable (Supporting Information). 315 Because the higher activity of sudemycin $\mathrm{K}$ was observed both 316 in short-term alternative splicing regulation of MCL1 and in 317 long-term increased cytotoxicity assays, the improved activity is 318 likely contributed both by direct effects on the splicing 319 machinery and by improved cell permeability or in vivo 320 stability. The replacement of the ester by an amide group could 321 make sudemycin $\mathrm{K}$ less sensitive to esterases, present for 322 example in plasma and microsomes ${ }^{50}$ and believed to be the 323 main factor responsible for the observed short in vivo half-life of 324 sudemycin $\mathrm{C} 1{ }^{45}$ Indeed, we observed higher stability of this 325 compound upon incubation in culture medium containing fetal 326 bovine serum (Figure 4). Replacing the isopropyl by a 327 carbamate (8, Figure 1) strongly reduced the compound 328 activity to levels undetectable in in vitro biochemical assays and very low-but still detectable-in cytotoxicity and alternative 329 splicing switching assays (Table 1, Figures 2G,H and 3). 330

Structure-Function Insights. Webb and colleagues 331 proposed that, despite their structural variety, natural 332 compounds targeting the SF3B complex share a common 333 pharmacophore structure. ${ }^{41}$ The pharmacophore was repeated 334 in the synthetic sudemycins that, in contrast with natural 335 compounds, are suitable for scalable production and display 336 improved stability and solubility. ${ }^{45,47}$ The common pharmaco- 337 phore hypothesis is also supported by recent results arguing 338 that herboxidiene, spliceostatin A, and pladienolide B bind to 339 the same site in the SF3B complex and likely share a common 340 inhibitory mechanism. ${ }^{51}$

341

A conjugated diene is one of the three key features of the 342 common pharmacophore. ${ }^{41}$ Cyclopropyl modifications in this 343 moiety were shown to reduce but not suppress the activity of 344 meayamycin's variants, suggesting that the diene needs to be in 345 trans configuration. ${ }^{52}$ We confirmed that conversion of the 346 diene to a single double bond suppresses activity. Surprisingly, 347 we also found that both the compound ha 0 ng a triene 348 moiety and the stereoisomer displaying a $Z, 1$, , onfiguration 349 retained some activity (particularly the latter in cytotoxicity 350 assays). This result reveals spatial flexibility around the 351 conjugated diene moiety, particularly regarding relative 352 orientation of the oxane ring and its associated ep roup, as 353 well as its spatial relationship with the oxycarbonyl moiety 354 (another key feature of the pharma ore) at the other end of 355 the molecule. Interestingly, the $Z, L, Z$ configuration opens the 356 possibility of versatile modification routes through Diels-Alder 357 reactions.

358

We also confirmed the need of cyclohexane or dioxane rings 359 for activity, with cyclohexane-containing drugs be 8 more 360 active. The more planar structure of piperazine disrup 2 rug's 361 activity, su ing that the spatial configuration of this moiety 362 is essential 2 splaying a proper orientation of the oxycarbonyl 363 and conjugated diene groups in the functional pharmacophore. 364 Substitution of the cyclohexyl group by a dioxane also reduced 365 strongly the drug's activity, further supporting the importance 366 of this structure.

367

The introduction of an amide group instead of the ester led 368 to a compound with improved splicing inhibitory activity and 369 cytotoxicity. While we only analyzed this variant in the context 370 of sudemycin molecules, we hypothesize that a similar 371 modification can have similar enhancing effects on the activity 372 of the other classes of compounds harboring a similar 373 pharmacophore, including pladienolides, herboxidienes, and 374 FR901464.

Given that compounds from parallel synthesis of the various 376 sudemycin analogs were tested, the higher activity of sudemycin 377 $\mathrm{K}$ can be attributed to the amide group and be associated both 378 with stronger direct effects on the splicing machinery, e.g., 379 improved affinity for the target, and with higher solubility and/ 380 or stability. As the solubility was found to be comparable to that 381 of sudemycin D6, the results of Figure 4 indeed argue for 382 improved stability, as expected if replacement of the oxy- 383 


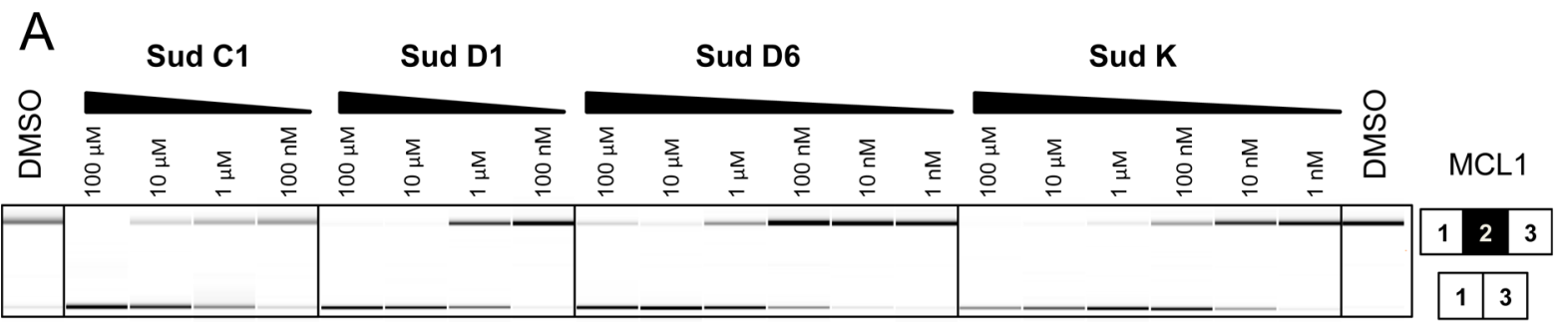

\section{$\begin{array}{lllll}\text { Sud E } & \text { Sud F1 } & \text { Sud F2 } & 4 & 1\end{array}$}

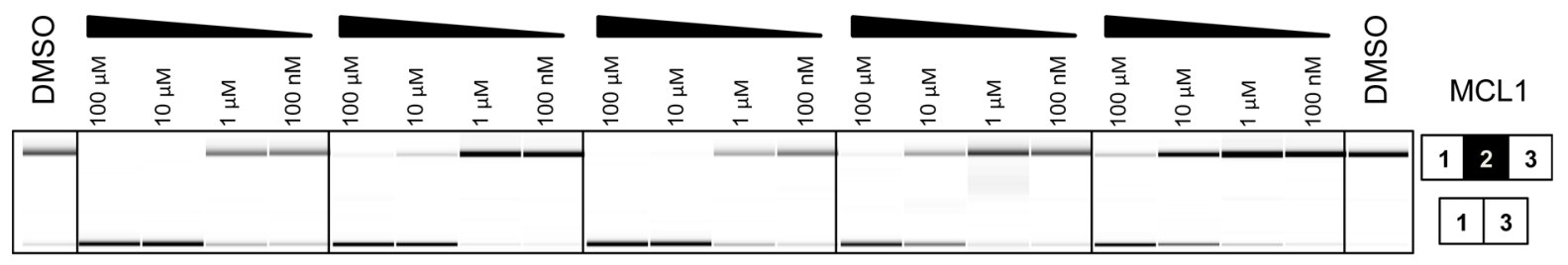

$\begin{array}{llllll}8 & 2 & 3 & 6 & 5 a & 5 b\end{array}$

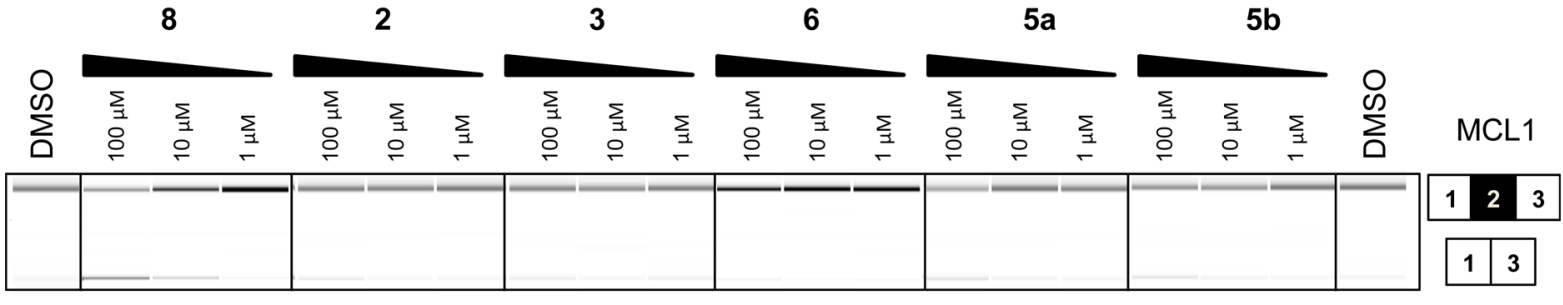

B

MCL1 - exon 2 inclusion

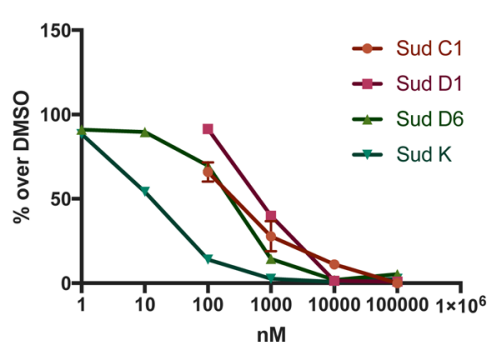

C

Viability at $72 \mathrm{~h}$

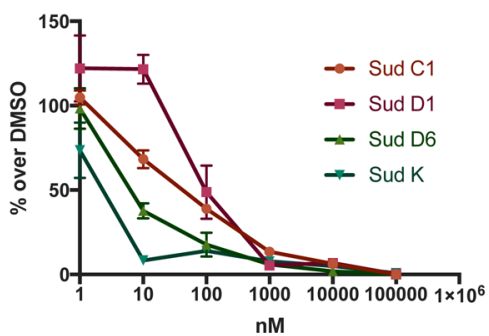

MCL1 - exon 2 inclusion

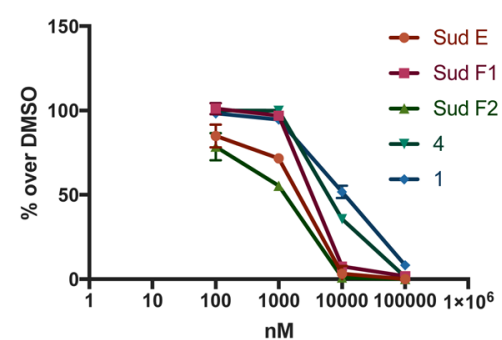

Viability at $72 \mathrm{~h}$

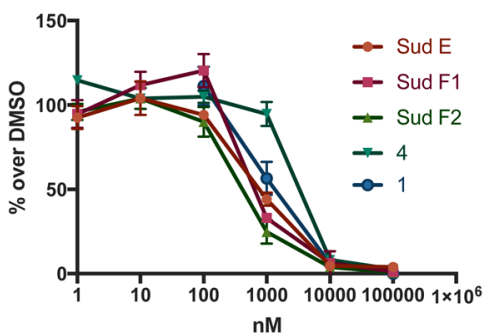

MCL1 - exon 2 inclusion

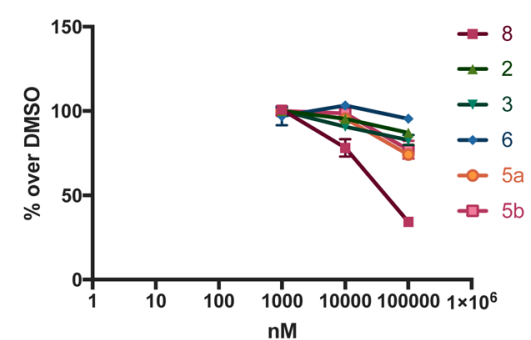

Viability at $72 \mathrm{~h}$

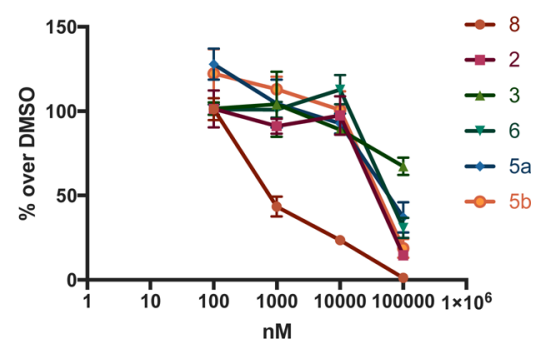

Figure 3. MCL1 alternative splicing and cytotoxicity assays in HeLa cells. (A) Capillary electrophoresis profiles of RT-PCR amplification of MCL1 alternatively spliced products from RNA isolated $3 \mathrm{~h}$ after drug exposure. The positions of the products corresponding to exon 2 inclusion and skipping are indicated, along with the drug treatment and concentrations (DMSO, control without drug). One representative example per condition is shown. (B) Quantification of data shown in A for duplicate experiments. Graphs represent \% of MCL1 exon 2 inclusion at different drug concentrations, as indicated. Drug treatments were clustered according to the different concentration ranges at which they induce exon 2 skipping. Standard deviations are shown. Higher activity of sudemycin K than sudemycin D6 was significant $(t$ test, $p$ value $<0.01)$. (C) Cytotoxicity assays. Cell viability was measured using Resazurin assays $72 \mathrm{~h}$ after drug exposure. Graphs indicate the fraction of living cells compared to control DMSO treatment. All treatments were performed in triplicate, and standard deviations are shown. Drug treatments were clustered according to the different concentration ranges at which they induce significant decreases in cell viability. Higher activity of sudemycin $\mathrm{K}$ than sudemycin D6 was significant $(t$ test, $p$ value $<0.01)$. 
Scheme 2. Syntheses of $5 \mathrm{a}, 5 \mathrm{~b}$, and $6^{a}$

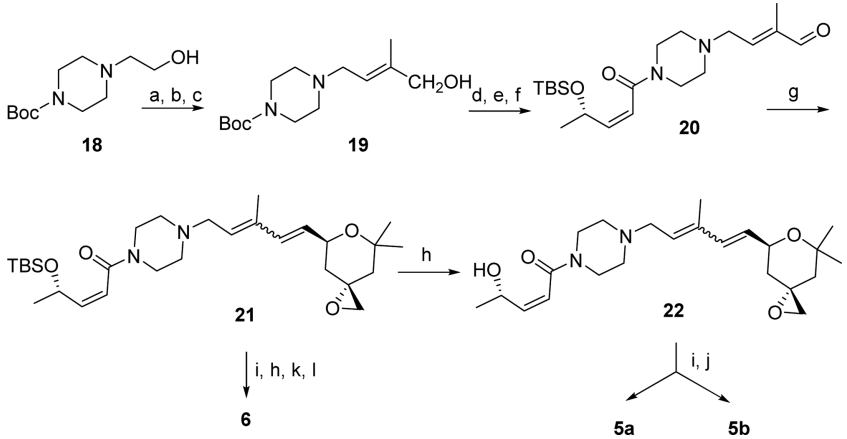

${ }^{a}$ Reagents and conditions: (a) $(\mathrm{COCl})_{2}, \mathrm{DMSO}, \mathrm{CH}_{2} \mathrm{Cl}_{2},-78{ }^{\circ} \mathrm{C}$, then $\mathrm{Et}_{3} \mathrm{~N}-78{ }^{\circ} \mathrm{C}$ to $\mathrm{rt}$; (b) (1-ethoxy-1-oxopropan-2-yl)triphenylphosphonium bromide, $t$ - $\mathrm{BuOK}, \mathrm{CH}_{2} \mathrm{Cl}_{2}, 0^{\circ} \mathrm{C}$ to rt $65 \%$ (2 steps); (c) DIBALH, $\mathrm{CH}_{2} \mathrm{Cl}_{2},-78{ }^{\circ} \mathrm{C}, 78 \%$; (d) TFA, $\mathrm{CH}_{2} \mathrm{Cl}_{2}, 0{ }^{\circ} \mathrm{C}$ to rt; (e) $(S, Z)$-4-(tert-butyldimethylsilyloxy)pent-2-enoic acid, $\mathrm{HBTU}, \mathrm{NEt}_{3}$, ACN, $0{ }^{\circ} \mathrm{C}$ to rt, $90 \%$ (2 steps); (f) Dess-Martin periodinane, $\mathrm{CH}_{2} \mathrm{Cl}_{2}$, $0{ }^{\circ} \mathrm{C}$, 78\%; (g) 11, NaHMDS, THF, $-78{ }^{\circ} \mathrm{C}$ to $\mathrm{rt}, 70 \%$; (h) TBAF, THF, $0{ }^{\circ} \mathrm{C}$ to rt, $67 \%$; (i) semipreparative RP-HPLC purification; $(\mathrm{j})$ isobutyric anhydride, $\mathrm{NEt}_{3}$, 4-DMAP, $\mathrm{CH}_{2} \mathrm{Cl}_{2}, 0{ }^{\circ} \mathrm{C}$, 98\%; (k) 4nitrophenyl chloroformate, $\mathrm{NEt}_{3}, \mathrm{CH}_{2} \mathrm{Cl}_{2}, 0{ }^{\circ} \mathrm{C}$ to $\mathrm{rt}, 45 \%$; (l) methylamine, $\mathrm{ClCH}_{2} \mathrm{CH}_{2} \mathrm{Cl}, 0{ }^{\circ} \mathrm{C}$ to $\mathrm{rt}, 75 \%$.

\section{Scheme 3. Synthesis of Sudemycin $\mathrm{K}$ and $8^{a}$}

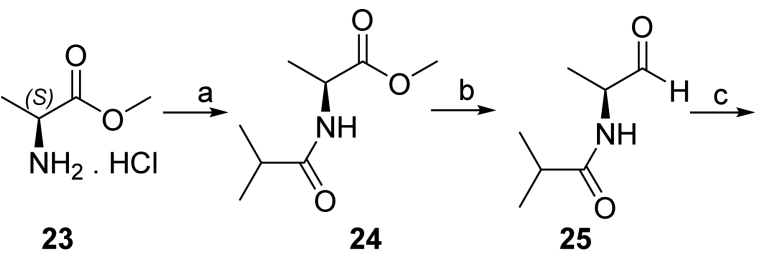

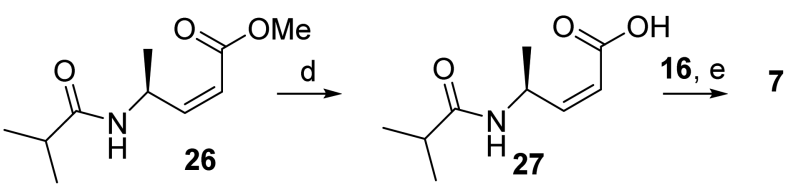<smiles>COC(=O)/C=C\[C@H](C)NC(=O)OC(C)(C)C(=O)N[C@H](C)/C=C\C(=O)OC(C)(C)C</smiles>

${ }^{a}$ Reagents and conditions: (a) Isobutyric anhydride, $\mathrm{NEt}_{3}, 4-\mathrm{DMAP}$, $\mathrm{CH}_{2} \mathrm{Cl}_{2}, 0{ }^{\circ} \mathrm{C}$, 99\%; (b) DIBALH, toluene, $-78{ }^{\circ} \mathrm{C}, 71 \%$; (c) KHMD S, 18 -crown-6, bis $(2,2,2$-trifluoroethyl $)$ (methoxycarbonylmethyl)phosphonate, THF, $-78{ }^{\circ} \mathrm{C}$, $82 \%$ for 26 , $72 \%$ for 29; (d) $\mathrm{Me}_{3} \mathrm{SnOH}, \mathrm{ClCH}_{2} \mathrm{CH}_{2} \mathrm{Cl}, 85{ }^{\circ} \mathrm{C}, 50 \%$ for $29,75 \%$ for 30; (e) (1) 16, $\mathrm{Ph}_{3} \mathrm{P}$, benzene, $55^{\circ} \mathrm{C}$; (2) acid 27 or 30, $\mathrm{HBTU}, \mathrm{NEt}_{3}$, ACN, $0{ }^{\circ} \mathrm{C}$ to rt, $30 \%$ (2 steps) for 7, 50\% (2 steps) for 8 . The overall yield of sudemycin $\mathrm{K}$ synthesis was $12 \%$, comparable to previous yields obtained for other Sudemycin variants. ${ }^{45-47}$

384 carbonyl by an amide group makes it no longer a substrate of 385 esterases, believed to be the main factor responsible for the 386 short half-life of sudemycin C1 in vivo. ${ }^{45,47}$ Jurica and colleagues 387 recently showed that both active compounds and their inactive 388 analogues compete for binding to the same site, suggesting that 389 the compounds' activities may rely upon a conformational
MCL1 - exon 2 skipping regulation

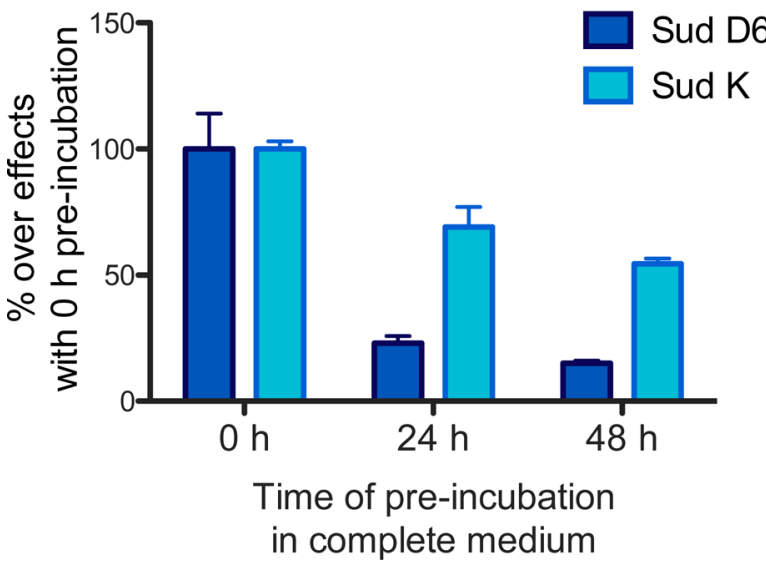

Figure 4. Stability of sudemycin D6 and sudemycin K upon incubation in culture medium with $10 \%$ fetal bovine serum. Complete culture medium containing $1 \mu \mathrm{M}$ drug or the equivalent volume of DMSO was incubated at $37^{\circ} \mathrm{C}$ for the indicated times and subsequently added to a lawn of HeLa cells. After $3 \mathrm{~h}$ of incubation, RNA was isolated and MCL1 alternative splicing was assessed as a measure of residual drug activity. Exon 2 inclusion levels upon DMSO treatment were used to normalize values across time points, and the levels of regulation induced at the $0 \mathrm{~h}$ time point by each drug were set at $100 \%$. The reduction of the effects at each time point is significantly low sudemycin $\mathrm{K}$ compared to sudemycin D6 ( $p$ value $<0.02$ at value $<0.001$ at $48 \mathrm{~h}$ by $t$ test comparison of duplicated treatments).

change within the SF3B complex induced (or prevented) only 390 by the active variants. ${ }^{51}$ Therefore, the different activity of 391 sudemycin variants, including the higher activity of sudemycin 392 $\mathrm{K}$, may be also due to more efficient modulation of such 393 conformational changes.

394

The amide moiety makes sudemycin $\mathrm{K}$ suitable for 395 conjugation with ureas, amides, and carbamates, potentially 396 generating a large variety of chemical derivatives, which once 397 again might be extrapolable to other families of splicing 398 inhibitors, like meayamycin, spliceostatin, and pladienolides. 399 Future work will focus on the generation and activity evaluation 400 of such derivatives.

In summary, in addition to confirming the importance of the 402 conjugated diene, our studies reveal that changes in the diene 403 configuration only partially decrease drug activity, while 404 replacement of a cyclohexane ring by piperazine abolishes it. 405 Finally, we obtained a compound with improved activity, at 406 least partly due to increased stability, sudemycin K, by replacing 407 the oxycarbonyl with an amide group. This variant offers 408 reactivity possibilities that can potentially expand significantly 409 the structural diversity of these drugs.

410

\section{METHODS}

411

Synthesis methods are summarized in the legends of Schemes 1-3 and 412 fully detailed, along with the characterization of synthetic products by 413 NMR and 2D correlation spectra, in the Supporting Information. 414 Biochemical and cellular assays were described before ${ }^{24,39}$ and fully 415 detailed in the Supporting Information.

\section{ASSOCIATED CONTENT}

416

\section{S Supporting Information}

417

The Supporting Information is available free of charge on the 419 ACS Publications website at DOI: 10.1021/acschem- 420 bio.6b00562. 
Material and Methods and Supporting Information Figure 1 (PDF)

\section{AUTHOR INFORMATION}

\section{Corresponding Authors}

426 *E-mail: juan.valcarcel@crg.eu.

427 *E-mail: mercedesalvarez@ub.edu.

428 ORCID

429 Fernando Albericio: 0000-0002-8946-04

430 Mercedes Álvarez: 0000-0002-2025-9111

\section{Present Addresses}

${ }_{432}$ Prof. Fernando Albericio, School of Chemistry and Physics, 433 University of KwaZulu-Natal, Durban, South Africa

${ }_{434}$ IT Dr. Kamil Makowski, School of Chemistry, YachayTech 435 University, Hacienda San Jose SN, San Miguel de Urcuqui 436 100119, Ecuador

\section{Author Contributions}

$438{ }^{\circ}$ Equal contribution

\section{Author Contributions}

$440{ }^{+}$These authors contributed equally.

\section{Notes}

442 The authors declare no competing financial interest.

\section{ACKNOWLEDGMENTS}

444 Work in our laboratories is supported by Fundación Botín, 445 Banco de Santander through its Santand piversities Global 446 Division, Consolider RNAREG, AGAUI d the European 447 Research Council. We acknowledge support of the Spanish 448 Ministry of Economy and Competitiveness, 'Centro de 449 Excelencia Severo Ochoa 2013-2017.' This work was partially 450 funded by the CICYT (CTQ2015-67870P) and Generalitat de 451 Catalunya (2014 SGR 137).

\section{ABBREVIATIONS}

453 Sud, sudemycin; SAR, structure-activity relationship; 4454 DMAP, 4-(dimethylamino)pyridine; ACN, acetonin DI455 BALH, diisobutylaluminum hydride; Bt, 2-benzo[ $\mathrm{C}$ - 7 zole; 456 DMSO, dimethyl sulfoxide; NaHMDS, sodium hexamethyldi457 silazane; KHMDS, potassium hexamethyldisilazane; TBAF, 458 tetrabutylammonium fluoride; THF, tetrahydrofuran

\section{$459 \square$ REFERENCES}

460 (1) Bonnal, S., Vigevani, L., and Valcarcel, J. (2012) The spliceosome 461 as a target of novel antitumour drugs. Nat. Rev. Drug Discovery 11, $462847-859$.

463 (2) Salton, M., and Misteli, T. (2016) Small Molecule Modulators of 464 Pre-mRNA Splicing in Cancer Therapy. Trends Mol. Med. 22, 28-37. 465 (3) Webb, T. R., Joyner, A. S., and Potter, P. M. (2013) The 466 development and application of small molecule modulators of SF3b as 467 therapeutic agents for cancer. Drug Discovery Today 18, 43-49.

468 (4) Hsu, T. Y., Simon, L. M., Neill, N. J., Marcotte, R., Sayad, A., 469 Bland, C. S., Echeverria, G. V., Sun, T., Kurley, S. J., Tyagi, S., Karlin, 470 K. L., Dominguez-Vidana, R., Hartman, J. D., Renwick, A., Scorsone, 471 K., Bernardi, R. J., Skinner, S. O., Jain, A., Orellana, M., Lagisetti, C., 472 Golding, I., Jung, S. Y., Neilson, J. R., Zhang, X. H., Cooper, T. A., 473 Webb, T. R., Neel, B. G., Shaw, C. A., and Westbrook, T. F. (2015) 474 The spliceosome is a therapeutic vulnerability in MYC-driven cancer. 475 Nature 525, 384-388.

476 (5) Hubert, C. G., Bradley, R. K., Ding, Y., Toledo, C. M., Herman, J., 477 Skutt-Kakaria, K., Girard, E. J., Davison, J., Berndt, J., Corrin, P., 478 Hardcastle, J., Basom, R., Delrow, J. J., Webb, T., Pollard, S. M., Lee, J., 479 Olson, J. M., and Paddison, P. J. (2013) Genome-wide RNAi screens in human brain tumor isolates reveal a novel viability requirement for 480 PHF5A. Genes Dev. 27, 1032-1045.

(6) Papasaikas, P., and Valcarcel, J. (2016) The Spliceosome: The 482 Ultimate RNA Chaperone and Sculptor. Trends Biochem. Sci. 41, 33- 483 45 .

(7) Wahl, M. C., Will, C. L., and Luhrmann, R. (2009) The 485 spliceosome: design principles of a dynamic RNP machine. Cell 136, 486 701-718.

(8) Yoshida, K., and Ogawa, S. (2014) Splicing factor mutations and 488 cancer. Wiley Interdiscip Rev. RNA 5, 445-459.

(9) Papaemmanuil, E., Cazzola, M., Boultwood, J., Malcovati, L., 490 Vyas, P., Bowen, D., Pellagatti, A., Wainscoat, J. S., Hellstrom- 491 Lindberg, E., Gambacorti-Passerini, C., Godfrey, A. L., Rapado, I., 492 Cvejic, A., Rance, R., McGee, C., Ellis, P., Mudie, L. J., Stephens, P. J., 493 McLaren, S., Massie, C. E., Tarpey, P. S., Varela, I., Nik-Zainal, S., 494 Davies, H. R., Shlien, A., Jones, D., Raine, K., Hinton, J., Butler, A. P., 495 Teague, J. W., Baxter, E. J., Score, J., Galli, A., Della Porta, M. G., 496 Travaglino, E., Groves, M., Tauro, S., Munshi, N. C., Anderson, K. C., 497 El-Naggar, A., Fischer, A., Mustonen, V., Warren, A. J., Cross, N. C., 498 Green, A. R., Futreal, P. A., Stratton, M. R., and Campbell, P. J. (2011) 499 Somatic SF3B1 mutation in myelodysplasia with ring sideroblasts. N. 500 Engl. J. Med. 365, 1384-1395.

(10) Yoshida, K., Sanada, M., Shiraishi, Y., Nowak, D., Nagata, Y., 502 Yamamoto, R., Sato, Y., Sato-Otsubo, A., Kon, A., Nagasaki, M., 503 Chalkidis, G., Suzuki, Y., Shiosaka, M., Kawahata, R., Yamaguchi, T., 504 Otsu, M., Obara, N., Sakata-Yanagimoto, M., Ishiyama, K., Mori, H., 505 Nolte, F., Hofmann, W. K., Miyawaki, S., Sugano, S., Haferlach, C., 506 Koeffler, H. P., Shih, L. Y., Haferlach, T., Chiba, S., Nakauchi, H., 507 Miyano, S., and Ogawa, S. (2011) Frequent pathway mutations of 508 splicing machinery in myelodysplasia. Nature 478, 64-69. 509

(11) Quesada, V., Conde, L., Villamor, N., Ordonez, G. R., Jares, P., 510 Bassaganyas, L., Ramsay, A. J., Bea, S., Pinyol, M., Martinez-Trillos, A., 511 Lopez-Guerra, M., Colomer, D., Navarro, A., Baumann, T., Aymerich, 512 M., Rozman, M., Delgado, J., Gine, E., Hernandez, J. M., Gonzalez- 513 Diaz, M., Puente, D. A., Velasco, G., Freije, J. M., Tubio, J. M., Royo, 514 R., Gelpi, J. L., Orozco, M., Pisano, D. G., Zamora, J., Vazquez, M., 515 Valencia, A., Himmelbauer, H., Bayes, M., Heath, S., Gut, M., Gut, I., 516 Estivill, X., Lopez-Guillermo, A., Puente, X. S., Campo, E., and Lopez- 517 Otin, C. (2012) Exome sequencing identifies recurrent mutations of 518 the splicing factor SF3B1 gene in chronic lymphocytic leukemia. Nat. 519 Genet. 44, 47-52.

(12) Rossi, D., Bruscaggin, A., Spina, V., Rasi, S., Khiabanian, H., 521 Messina, M., Fangazio, M., Vaisitti, T., Monti, S., Chiaretti, S., Guarini, 522 A., Del Giudice, I., Cerri, M., Cresta, S., Deambrogi, C., Gargiulo, E., 523 Gattei, V., Forconi, F., Bertoni, F., Deaglio, S., Rabadan, R., 524 Pasqualucci, L., Foa, R., Dalla-Favera, R, and Gaidano, G. (2011) 525 Mutations of the SF3B1 splicing factor in chronic lymphocytic 526 leukemia: association with progression and fludarabine-refractoriness. 527 Blood 118, 6904-6908.

528

(13) Wang, L., Lawrence, M. S., Wan, Y., Stojanov, P., Sougnez, C., 529 Stevenson, K., Werner, L., Sivachenko, A., DeLuca, D. S., Zhang, L., 530 Zhang, W., Vartanov, A. R., Fernandes, S. M., Goldstein, N. R., Folco, 531 E. G., Cibulskis, K., Tesar, B., Sievers, Q. L., Shefler, E., Gabriel, S., 532 Hacohen, N., Reed, R., Meyerson, M., Golub, T. R., Lander, E. S., 533 Neuberg, D., Brown, J. R., Getz, G., and Wu, C. J. (2011) SF3B1 and 534 other novel cancer genes in chronic lymphocytic leukemia. N. Engl. J. 535 Med. 365, 2497-2506.

(14) Albert, B. J., McPherson, P. A., O’Brien, K., Czaicki, N. L., 537 Destefino, V., Osman, S., Li, M., Day, B. W., Grabowski, P. J., Moore, 538 M. J., Vogt, A., and Koide, K. (2009) Meayamycin inhibits pre- 539 messenger RNA splicing and exhibits picomolar activity against 540 multidrug-resistant cells. Mol. Cancer Ther. 8, 2308-2318.

(15) Convertini, P., Shen, M., Potter, P. M., Palacios, G., Lagisetti, C., 542 de la Grange, P., Horbinski, C., Fondufe-Mittendorf, Y. N., Webb, T. 543 R. and Stamm, S. (2014) Sudemycin E influences alternative splicing 544 and changes chromatin modifications. Nucleic Acids Res. 42, 4947- 545 4961.

(16) Hasegawa, M., Miura, T., Kuzuya, K., Inoue, A., Won Ki, S., 547 Horinouchi, S., Yoshida, T., Kunoh, T., Koseki, K., Mino, K., Sasaki, R., 548 
549 Yoshida, M., and Mizukami, T. (2011) Identification of SAP155 as the 550 target of GEX1A (Herboxidiene), an antitumor natural product. ACS 551 Chem. Biol. 6, 229-233.

552 (17) Kaida, D., Motoyoshi, H., Tashiro, E., Nojima, T., Hagiwara, M., 553 Ishigami, K., Watanabe, H., Kitahara, T., Yoshida, T., Nakajima, H., 554 Tani, T., Horinouchi, S., and Yoshida, M. (2007) Spliceostatin A 555 targets SF3b and inhibits both splicing and nuclear retention of pre556 mRNA. Nat. Chem. Biol. 3, 576-583.

557 (18) Kotake, Y., Sagane, K., Owa, T., Mimori-Kiyosue, Y., Shimizu, 558 H., Uesugi, M., Ishihama, Y., Iwata, M., and Mizui, Y. (2007) Splicing 559 factor SF3b as a target of the antitumor natural product pladienolide. 560 Nat. Chem. Biol. 3, 570-575.

561 (19) Liu, X., Biswas, S., Tang, G. L., and Cheng, Y. Q. (2013) 562 Isolation and characterization of spliceostatin $\mathrm{B}$, a new analogue of 563 FR901464, from Pseudomonas sp. No. 2663. J. Antibiot. 66, 555-558. 564 (20) Nakajima, H., Sato, B., Fujita, T., Takase, S., Terano, H., and 565 Okuhara, M. (1996) New antitumor substances, FR901463, FR901464 566 and FR901465. I. Taxonomy, fermentation, isolation, physico-chemical 567 properties and biological activities. J. Antibiot. 49, 1196-1203.

568 (21) Sakai, T., Sameshima, T., Matsufuji, M., Kawamura, N., Dobashi, 569 K., and Mizui, Y. (2004) Pladienolides, new substances from culture of 570 Streptomyces platensis Mer-11107. I. Taxonomy, fermentation, 571 isolation and screening. J. Antibiot. 57, 173-179.

572 (22) Sakai, Y., Yoshida, T., Ochiai, K., Uosaki, Y., Saitoh, Y., Tanaka, 573 F., Akiyama, T., Akinaga, S., and Mizukami, T. (2002) GEX1 574 compounds, novel antitumor antibiotics related to herboxidiene, 575 produced by Streptomyces sp. I. Taxonomy, production, isolation, 576 physicochemical properties and biological activities. J. Antibiot. 55, 577 855-862.

578 (23) Seki-Asano, M., Okazaki, T., Yamagishi, M., Sakai, N., 579 Takayama, Y., Hanada, K., Morimoro, S., Takatsuki, A., and Mizoue, $580 \mathrm{~K}$. (1994) Isolation and characterization of a new 12-membered 581 macrolide FD-895. J. Antibiot. 47, 1395-1401.

582 (24) Corrionero, A., Minana, B., and Valcarcel, J. (2011) Reduced 583 fidelity of branch point recognition and alternative splicing induced by 584 the anti-tumor drug spliceostatin A. Genes Dev. 25, 445-459.

585 (25) Folco, E. G., Coil, K. E., and Reed, R. (2011) The anti-tumor 586 drug E7107 reveals an essential role for SF3b in remodeling U2 587 snRNP to expose the branch point-binding region. Genes Dev. 25, $588440-444$.

589 (26) Alsafadi, S., Houy, A., Battistella, A., Popova, T., Wassef, M., 590 Henry, E., Tirode, F., Constantinou, A., Piperno-Neumann, S., Roman591 Roman, S., Dutertre, M., and Stern, M. H. (2016) Cancer-associated 592 SF3B1 mutations affect alternative splicing by promoting alternative 593 branchpoint usage. Nat. Commun. 7, 10615.

594 (27) Darman, R. B., Seiler, M., Agrawal, A. A., Lim, K. H., Peng, S., 595 Aird, D., Bailey, S. L., Bhavsar, E. B., Chan, B., Colla, S., Corson, L., 596 Feala, J., Fekkes, P., Ichikawa, K., Keaney, G. F., Lee, L., Kumar, P., 597 Kunii, K., MacKenzie, C., Matijevic, M., Mizui, Y., Myint, K., Park, E. 598 S., Puyang, X., Selvaraj, A., Thomas, M. P., Tsai, J., Wang, J. Y., 599 Warmuth, M., Yang, H., Zhu, P., Garcia-Manero, G., Furman, R. R., $600 \mathrm{Yu}$, L., Smith, P. G., and Buonamici, S. (2015) Cancer-Associated 601 SF3B1 Hotspot Mutations Induce Cryptic 3? Splice Site Selection 602 through Use of a Different Branch Point. Cell Rep. 13, 1033-1045.

603 (28) David, C. J., and Manley, J. L. (2010) Alternative pre-mRNA 604 splicing regulation in cancer: pathways and programs unhinged. Genes 605 Dev. 24, 2343-2364.

606 (29) Larrayoz, M., Blakemore, S. J., Dobson, R. C., Blunt, M. D., 607 Rose-Zerilli, M. J., Walewska, R., Duncombe, A., Oscier, D., Koide, K., 608 Forconi, F., Packham, G., Yoshida, M., Cragg, M. S., Strefford, J. C., 609 and Steele, A. J. (2016) The SF3B1 inhibitor spliceostatin A (SSA) 610 elicits apoptosis in chronic lymphocytic leukaemia cells through 611 downregulation of Mcl-1. Leukemia 30, 351-360.

612 (30) Salton, M., Kasprzak, W. K., Voss, T., Shapiro, B. A., Poulikakos, 613 P. I., and Misteli, T. (2015) Inhibition of vemurafenib-resistant 614 melanoma by interference with pre-mRNA splicing. Nat. Commun. 6, 6157103.

616 (31) Lee, S. C., Dvinge, H., Kim, E., Cho, H., Micol, J. B., Chung, Y. 617 R., Durham, B. H., Yoshimi, A., Kim, Y. J., Thomas, M., Lobry, C.,
Chen, C. W., Pastore, A., Taylor, J., Wang, X., Krivtsov, A., Armstrong, 618 S. A., Palacino, J., Buonamici, S., Smith, P. G., Bradley, R. K., and 619 Abdel-Wahab, O. (2016) Modulation of splicing catalysis for 620 therapeutic targeting of leukemia with mutations in genes encoding 621 spliceosomal proteins. Nat. Med. 22, 672-678.

(32) Xargay-Torrent, S., Lopez-Guerra, M., Rosich, L., Montraveta, 623 A., Roldan, J., Rodriguez, V., Villamor, N., Aymerich, M., Lagisetti, C., 624 Webb, T. R., Lopez-Otin, C., Campo, E., and Colomer, D. (2015) The 625 splicing modulator sudemycin induces a specific antitumor response 626 and cooperates with ibrutinib in chronic lymphocytic leukemia. 627 Oncotarget 6, 22734-22749.

(33) Glaser, S. P., Lee, E. F., Trounson, E., Bouillet, P., Wei, A., 629 Fairlie, W. D., Izon, D. J., Zuber, J., Rappaport, A. R., Herold, M. J., 630 Alexander, W. S., Lowe, S. W., Robb, L., and Strasser, A. (2012) Anti- 631 apoptotic Mcl-1 is essential for the development and sustained growth 632 of acute myeloid leukemia. Genes Dev. 26, 120-125.

(34) Tiedemann, R. E., Zhu, Y. X., Schmidt, J., Shi, C. X., Sereduk, C., 634 Yin, H., Mousses, S., and Stewart, A. K. (2012) Identification of 635 molecular vulnerabilities in human multiple myeloma cells by RNA 636 interference lethality screening of the druggable genome. Cancer Res. 637 $72,757-768$.

638

(35) Wei, G., Margolin, A. A., Haery, L., Brown, E., Cucolo, L., Julian, 639 B., Shehata, S., Kung, A. L., Beroukhim, R., and Golub, T. R. (2012) 640 Chemical genomics identifies small-molecule MCL1 repressors and 641 BCL-xL as a predictor of MCL1 dependency. Cancer Cell 21, 547- 642 562.

(36) Bae, J., Leo, C. P., Hsu, S. Y., and Hsueh, A. J. (2000) MCL-1S, 644 a splicing variant of the antiapoptotic BCL-2 family member MCL-1, 645 encodes a proapoptotic protein possessing only the BH3 domain. J. 646 Biol. Chem. 275, 25255-25261.

(37) Laetsch, T. W., Liu, X., Vu, A., Sliozberg, M., Vido, M., Elci, O. 648 U., Goldsmith, K. C., and Hogarty, M. D. (2014) Multiple 649 components of the spliceosome regulate Mcl1 activity in neuro- 650 blastoma. Cell Death Dis. 5, e1072.

(38) Moore, M. J., Wang, Q., Kennedy, C. J., and Silver, P. A. (2010) 652 An alternative splicing network links cell-cycle control to apoptosis. 653 Cell 142, 625-636.

654

(39) Papasaikas, P., Tejedor, J. R., Vigevani, L., and Valcarcel, J. 655 (2015) Functional splicing network reveals extensive regulatory 656 potential of the core spliceosomal machinery. Mol. Cell 57, 7-22. 657

(40) Gao, Y., and Koide, K. (2013) Chemical perturbation of Mcl-1 658 pre-mRNA splicing to induce apoptosis in cancer cells. ACS Chem. 659 Biol. 8, 895-900.

(41) Lagisetti, C., Pourpak, A., Jiang, Q., Cui, X., Goronga, T., 661 Morris, S. W., and Webb, T. R. (2008) Antitumor compounds based 662 on a natural product consensus pharmacophore. J. Med. Chem. 51, 663 $6220-6224$.

(42) He, H., Ratnayake, A. S., Janso, J. E., He, M., Yang, H. Y., 665 Loganzo, F., Shor, B., O’Donnell, C. J., and Koehn, F. E. (2014) 666 Cytotoxic Spliceostatins from Burkholderia sp. and Their Semi- 667 synthetic Analogues. J. Nat. Prod. 77, 1864-1870.

(43) Liu, X., Biswas, S., Berg, M. G., Antapli, C. M., Xie, F., Wang, O. 669 Tang, M. C., Tang, G. L., Zhang, L., Dreyfuss, G., and Cheng, Y. Q. 670 (2013) Genomics-guided discovery of thailanstatins A, B, and C As 671 pre-mRNA splicing inhibitors and antiproliferative agents from 672 Burkholderia thailandensis MSMB43. J. Nat. Prod. 76, 685-693. 673

(44) Villa, R., Kashyap, M. K., Kumar, D., Kipps, T. J., Castro, J. E., 674 La Clair, J. J., and Burkart, M. D. (2013) Stabilized cyclopropane 675 analogs of the splicing inhibitor FD-895. J. Med. Chem. 56, 6576-6582. 676 (45) Fan, L., Lagisetti, C., Edwards, C. C., Webb, T. R, and Potter, P. 677 M. (2011) Sudemycins, novel small molecule analogues of FR901464, 678 induce alternative gene splicing. ACS Chem. Biol. 6, 582-589. 679

(46) Lagisetti, C., Pourpak, A., Goronga, T., Jiang, Q., Cui, X., Hyle, 680 J., Lahti, J. M., Morris, S. W., and Webb, T. R. (2009) Synthetic 681 mRNA splicing modulator compounds with in vivo antitumor activity. 682 J. Med. Chem. 52, 6979-6990.

(47) Lagisetti, C., Palacios, G., Goronga, T., Freeman, B., Caufield, 684 W., and Webb, T. R. (2013) Optimization of antitumor modulators of 685 pre-mRNA splicing. J. Med. Chem. 56, 10033-10044. 
687 (48) Valverde, S., Martin-Lomas, M., Herradon, B., and Garcia688 Ochoa, S. (1987) The reaction of carbohydrate-derived alkoxyalde689 hydes with methoxycarbonylmethylenetriphenylphosphorane: stereo690 selective synthesis of $\beta$-unsaturated esters. Tetrahedron 43, 1895-1901. 691 (49) Seidl, P. R., Leal, K. Z., Costa, V. E. U., and Mollmann, M. E. S. 692 (1998) Steric effects on carbon-13 NMR shifts: carbon-hydrogen 693 bond polarim contributions. Magn. Reson. Chem. 36, 261-266.

694 (50) Casey Uure, S., Herring, V., Hu, Z., Witbrodt, K., and Parker, 695 R. B. (2013) The role of human carboxylesterases in drug metabolism: 696 have we overlooked their importance? Pharmacotherapy 33, 210-222. 697 (51) Effenberger, K. A., Urabe, V. K., Prichard, B. E., Ghosh, A. K., 698 and Jurica, M. S. (2016) Interchangeable SF3B1 inhibitors interfere 699 with pre-mRNA splicing at multiple stages. RNA 22, 350-359.

700 (52) Osman, S., Albert, B. J., Wang, Y., Li, M., Czaicki, N. L., and 701 Koide, K. (2011) Structural requirements for the antiproliferative 702 activity of pre-mRNA splicing inhibitor FR901464. Chem. - Eur. J. 17, 703 895-904. 